\title{
Analysis of long-span bridge fluctuations for finding its optimal safe operation
}

\author{
Elena Smirnova ${ }^{*}$ \\ ${ }^{1}$ St. Petersburg State University of Architecture and Civil Engineering, Vtoraja Krasnoarmejskaja ul. \\ 4, 190005 St. Petersburg, Russia
}

\begin{abstract}
The paper studies the intense oscillations sustained by the Volgogradsky Bridge on May 20, 2010. The studies were carried out based on physical and mathematical experiments. The introduction indicates the causes of emergence of the intense aeroelastic oscillations. Description is given of the physical nature of one of the types of these oscillations, i.e. stall flutter. Catastrophes are considered that had been caused by the flutter. Methodological fundamentals of the experiment are named and modern software capabilities of computer-aided fluid and gas dynamics are listed. The results of the experiment are supplied, including visualization of the Karman vortex street and determination of the Strouhal number. The recalculation of the experimental data to natural conditions is substantiated. A description is given of calculation of the bridge's aeroelastic oscillations. The main results of the aerodynamic calculation are supplied: the Strouhal numbers and critical velocities. The results of mathematical and physical experiments tallied well. A tally of the calculation and estimated full-scale results is pointed out. Results of this calculation (bridge oscillation amplitudes) are supplied. The conclusions point to the prospective viability of the mathematical experiment method. The proposed methods can minimize risks for the construction of long-span girder bridges, ensuring the precise estimation of their subsequent safe operation.
\end{abstract}

\section{Introduction}

"The dancing bridge": The oscillation and destruction of bridges have been studied for over two centuries. Among thousands of works on the subject worth a special note are recent studies [1-12]. Those offer essential provisions concerning the aerodynamics of bridges and the causes of their oscillation and destruction.

The bridge across the Volga, whose operation began in September 2009, was closed on 20 May, 2010, because of the suddenly arisen intense oscillations. This effect was named "the dancing bridge" (Fig. 1).

\footnotetext{
* Corresponding author: esmirnovae@ yandex.ru
} 

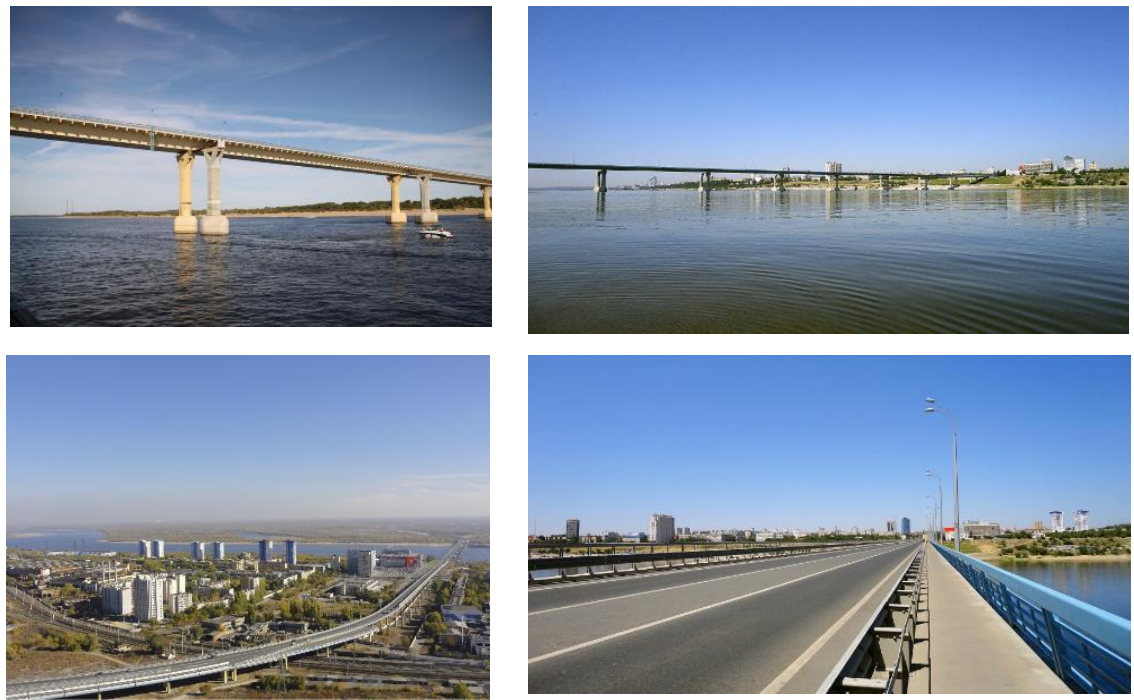

Fig. 1. Bridge across the Volga River in Volgograd.

A number of articles are devoted to the Volgogradsky Bridge oscillations that take into account the foreign experience in the study of this problem. We mention several, which we believe are particularly interesting [13-16]. So, the articles express an opinion that the intense oscillations of the Volgogradsky Bridge are actually self-excited oscillations brought about by aeroelestic processes. The upper structure of the bridge, located mainly on its spans of 155 $\mathrm{m}$ long, was oscillated. The oscillation frequency was of the order of $v \sim 0.5 \mathrm{~Hz}$. The vibrations were almost purely bending, there were no signs of noticeable torsion of the bridge canvas (Fig. 2).
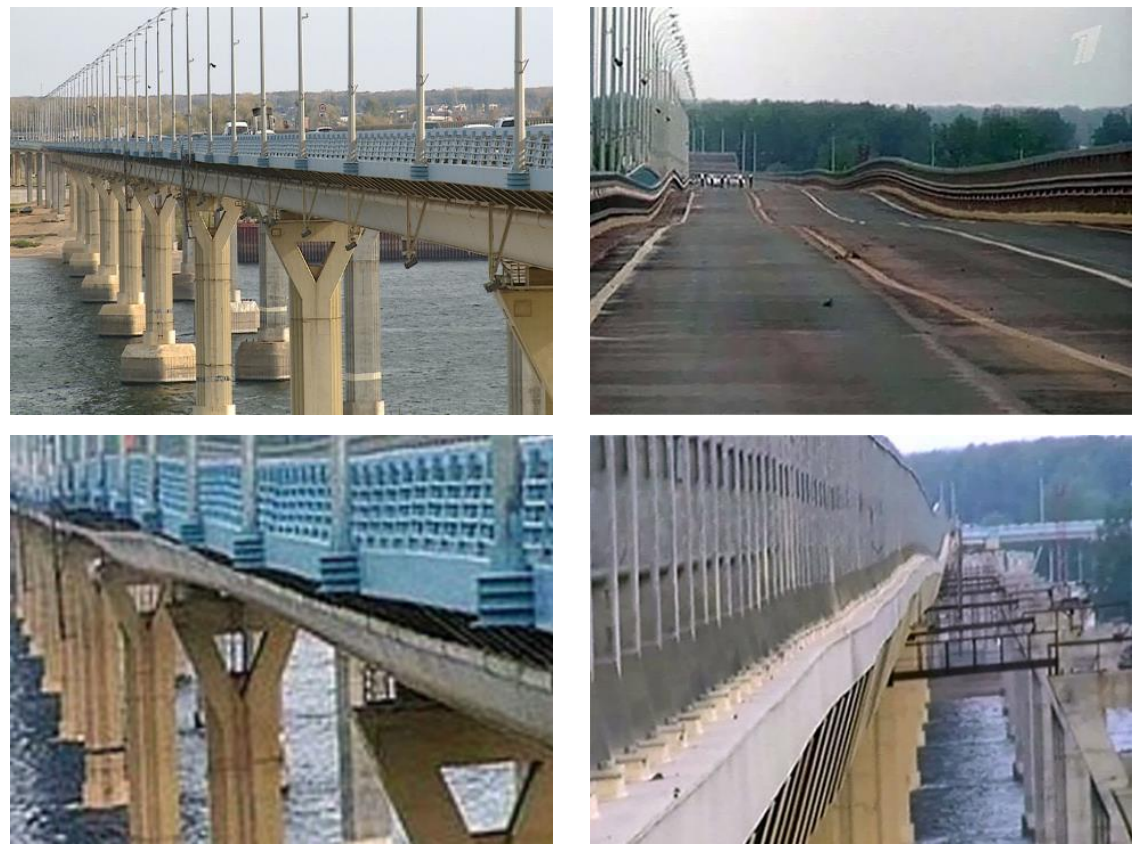

Fig. 2. Volgogradsky Bridge oscillations (the bridge before and during a period of intense oscillations). 
Based on estimation of flutter parameters of the Volgogradsky bridge a conclusion is drawn that the Strouhal number $(S h=0.092)$ and the Reinhold number $\left(R e=3.6 \cdot 10^{6}\right)$ almost coincide with measurements made for Tacoma Narrows Bridge (USA). Some authors reject altogether the hypothesis of self-excited oscillations brought about by the Karman vortexes shedding from the object on the grounds that it was not corroborated by the 20 May 2010 events. According to them, the most likely cause of the bridge oscillations is the explosion of ammunition with expired shelf life on the test range located roughly $50 \mathrm{~km}$ from Volgograd. Some authors believe it is not unlikely that over the past years the bridge had gotten into the stall flutter just only because it had sustained the blowing of a strong wind. The interaction of the Karman vortexes with the oscillating body ensures the positive feedback in the oscillating system. Most commonly, the stall flutter occurs when one of the proper oscillation frequencies of the body is close to or divisible by that of vortex shedding from the same body when it is immobile. The stall flutter starts when the wind velocity exceeds a certain critical value.

In our opinion, the "dancing bridge" phenomenon could take place only half a year after normal operation of the Volgogradsky Bridge since it is prone to happen at the unlikely set of the circumstances. We show below, based on results of experiment, that "the dancing bridge" is a manifestation of a rare case of the stall flutter. Under such circumstances the bridge oscillations featured a flexural pattern. It should be noted that the cross section design of the Volgogradsky Bridge span structure is typical, in terms of aerodynamics, for Russian long span girder bridges. Such phenomena of aeroelastic instability of bridges as galloping, divergence, stall or flexural-torsional flutter, and buffering are in principle impossible for the Volgogradsky type of bridge due to its cross section's geometrical specifics. The most likely cause of oscillations is the vortex excitement when the vortex stall frequency at the transversal overflowing of the span structure coincides with the span structure's proper oscillation frequency. This particular structural model of the bridge in the form of a multiplespan uncut system with maximum spans of $155 \mathrm{~m}$ such a structure is categorized as extremely flexible due to the very low flexural rigidity with an infra-low frequency (down to $1 \mathrm{~Hz}$ ) spectrum. As to the dangerous natural phenomena, the critical issue here is the aerodynamic stability of modern span structures of cable-stayed and, in some cases, uncut girder systems. Given below is the study on the flutter of the Volgogradsky Bridge by means of experimental method.

\section{Method}

It the world practice a strategy is accepted that determines the wind impact in two stages: the evaluative calculation of impacts on and tests of a prototype (simulator) in an aerodynamic tunnel, which prototype is fitted with sensors for static and dynamic measurements. As a rule, aerodynamic tunnels of different designs and sizes are used. In doing so, it is presumed that the tests on large-scale prototypes give a more detailed and precise picture of the wind impact. The results obtained during tests in the aerodynamic tunnel are transposed to the real facility with different precision factors.

The possibility of determining the discussed frequency on physical prototypes of the bridges with subsequent re-calculation as per real conditions is based on an experimentally established fact: most of the cross sections of elongated bodies are regardless of the scale of the overflowed structure [17-21]. In other words, the cross sections of elongated bodies overflowed by a flow of non-dimensional frequency of vortex shedding (Strouhal number) do not depend on the scale of the object:

$$
S h=\frac{n \cdot h}{V}
$$


where $n$ is a frequency of cortex shedding in $\mathrm{Hz}, h$ is the structure size transversal to the incoming flow, $V$ is velocity of incoming flow. This statement is highly likely to be true with reference to bodies whose cross-section has angular points [22]. Such bodies normally include the span bridge structures [23-25].

Currently in operation are methods based on the use of turbulence simulation. Such simulated models have been developed expressly for considering the turbulence effects without using the precision net and the direct numerical solution. The essence of such models stems from the supposition of the existence of a mean flow velocity and a mean deviation from it:

$$
u=\bar{u}+u^{\prime},
$$

where $u$ is the flow velocity, $\bar{u}$ is the mean flow velocity, $u_{i}^{\prime}$ is the mean deviation from the flow speed, $u_{i}^{\prime} u_{j}^{\prime \prime}$ is the product of mean deviations from the flow velocity. Following simplification of the Navier-Stokes equations, there emerge in them the products of mean deviations $u_{i}^{\prime} u_{j}^{\prime \prime}$. Different models simulate them differently. The use of a specific model in engineering computations depends on the need for a specific precision [26-27]. Modern software like ANSYS, SCAD, and ING+ enables a dynamic computing of structures sustaining oscillatory wind loads [28-30]. The turbulence models are realized in modern computing software applied to hydrodynamic flows such as Autodesk Simulation CFD, Fluent, CFX or OpenFOAM. For describing small-scale movements, the ANSYS CFX software uses the Smagorinsky model (ANSYS CFX 12.1, 2010) with two different walladjacent damping functions. For computing the aeroelastic instability in CFX it is possible to use the fluid structure interaction (FSI) technology that enables solution of problems of bilateral interaction of oscillations of the structure and aerodynamics. The CFD software is a tool for determining aerodynamic parameters. For a specific situation and specific conditions of loading it is necessary to develop an own computing method applicable to aeroelastic processes. Such a method, applicable to the Volgogradsky Bridge, is described below.

\section{Results}

The formation of self-excited oscillations needs a source of energy and certain capabilities of the dynamic system. In the case under consideration it's the wind that operates as a source of energy. The specific dynamics of the system is determined by its frequency, oscillation form and dissipative capabilities (damping coefficient). Referred to the aeroelastic selfexcited oscillations are various forms of aerodynamic instability of structures (galloping, flexural and torsional flutter, buffeting) and other oscillations associated with the vortex shedding on the outside of the buildings, including those accompanied by formation of the Karman vortex street (stall flutter). Fig. 3 presents the results of the first numerical calculations of the flutter of the Volgogradsky Bridge under the guidance of prof. Salenko (NSTU) from Novosibirsk. In such cases the oscillations occur in a direction perpendicular to the mean wind velocity (transversal oscillations).

Most commonly, the stall flutter occurs when one of the proper oscillation frequencies of the structure is close to or divisible by the frequency of vortex shedding of the same structure when it is immobile. The stall flutter was repeatedly observed on a number of engineering installations, such as many suspended bridges, factory steel pipes, helicopter propellers, submarine periscopes, compressor blades, turbines in turbojet engines, ship cables lowered into the ocean, etc. 


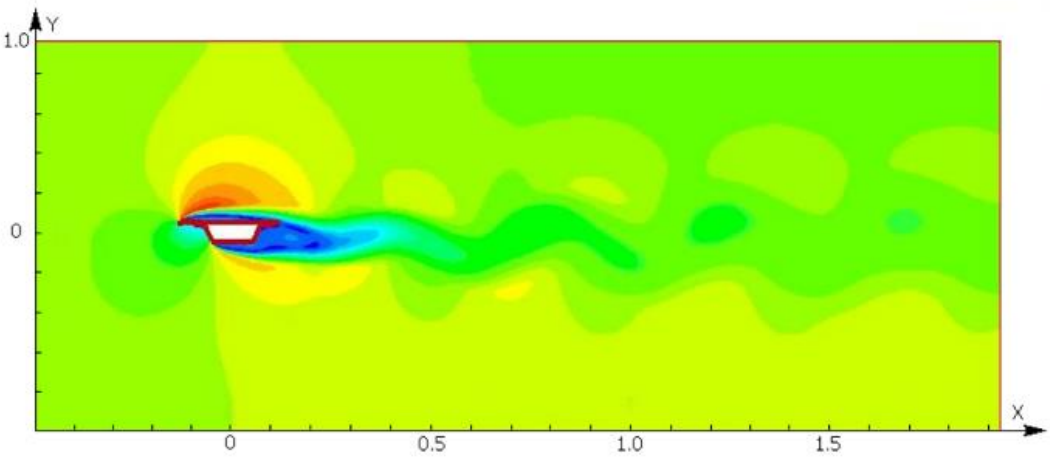

light green color $-V=16 \mathrm{~m} / \mathrm{s}$ (near the bridge span),

Pdark blue $-V=2 \mathrm{~m} / \mathrm{s}$,

Pred $-V=21.3 \mathrm{~m} / \mathrm{s}$.

Fig. 3. Visualization of the Karman vortex wake in the Volgogradsky Bridge span simulator.

Also, it is known that the stall flutter is the cause of many engineering disasters. The best known of them is the so called Tacoma Bridge collapse that occurred in USA in 1940 when a 854 m span cable-stayed bridge broke down under the impact of wind (Fig. 4).
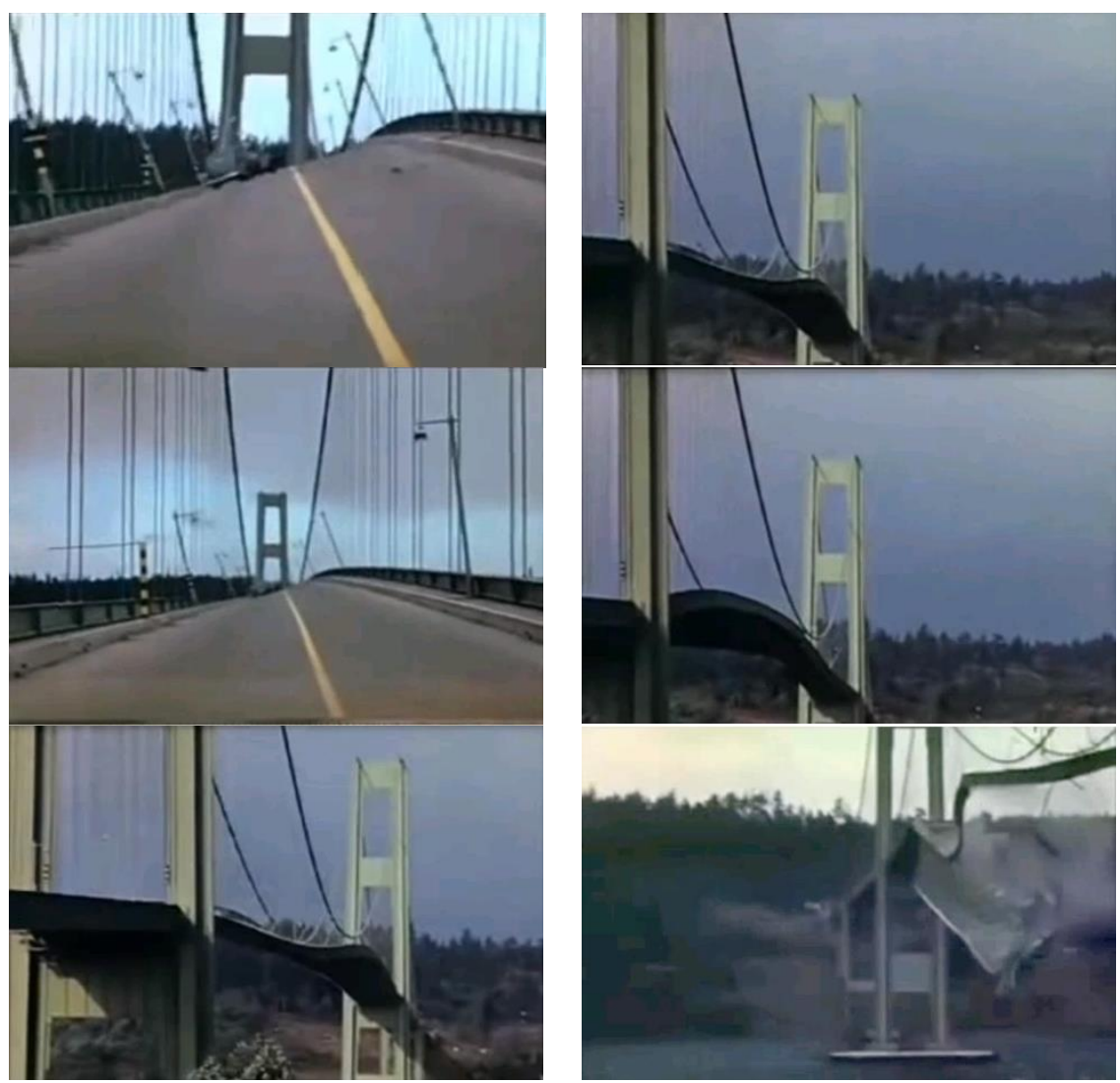

Fig. 4. Tacoma Narrows Bridge collapse "Galloping Gertie" November 7, 1940. 
The bridge became famous as the most dramatic failure in bridge engineering history. The collapse occurred after four months of use. According to Hobbs (2006) [31], Arioli and Gazzola (2017) [32], the principal cause of the collapse are the excessive dynamic torsional oscillations resulting from the vortex shedding. The study of this bridge's collapse was facilitated by the felicitous fact that the bridge behavior could be precisely monitored, from the start of the collapse to the crash moment, by filming that registered the oscillations and the nature of destruction. The rupture of the central span suspensions caused the sagging of the lateral spans and pylon inclination. The film shots show the bridge oscillating violently at the wind velocity of $18.8 \mathrm{~m} / \mathrm{s}$. The bridge had been designed to sustain the static stress at the wind velocity of up to $50 \mathrm{~m} / \mathrm{s}$. Not so tragic events took place in 1993 while building, by the launching method, a bridge across the Ob' River in Barnaul. At the three-girder console's boom extension of around $80 \mathrm{~m}$ and the wind velocity of 12 to $14 \mathrm{~m} / \mathrm{s}$, intense oscillations occurred on the 1,000-ton structure with $1 \mathrm{~m}$ span. It is often believed that the stall flutter usually associates with aeroelastic oscillations of torsional or flexural and torsional type. However, this is not so. The stall flutter can also occur at purely flexural oscillations.

In case of the bridge spans being cross-overflowed by air, variable and virtually periodic aerodynamic forces occur on them in the vertical direction. The said forces arise from the periodic vortex shedding from the lower and upper surfaces of the span structure and the resultant pressure pulsations. The main temporal frequency of the oscillatory stress coincides with the vortex shedding frequency. The importance of determining the said frequency of changing of aerodynamic stress at various wind velocities results from the possible resonance phenomena in the overflowing of the specific structure when the structure's proper oscillation frequency in one of the first tones may correspond to the oscillation frequency of the aerodynamic coercive force. That is expressly when the stall flutter takes effect. From the said, it is evident that the stall flutter can arise in a relatively narrow wind velocity range and at its certain predominant direction. Put differently, the flutter occurs at a rare combination of the said parameters.

Investigations were carried out on this installation aimed at studying the structure of the flow near the simulator of the Volgogradsky Bridge span structure. The large difference in values of Reinhold numbers during the hydrodynamic tunnel experiments and during the overflowing of the full-scale body influences but little the interaction of vortexes between themselves and with the surface of the body being overflowed. This results from the fact that the dynamics and kinematics of vortex systems are determined mainly by interaction of pressure and inertia forces impacting the fluid particles. This is precisely why the theory of ideal fluid $(R e=\infty)$ became widely used in many areas of applied hydromechanics. In his hydrodynamic tunnel Werlé studied the vortex systems arising during the overflowing of the Concord supersonic passenger airliner. The applicability of using the Strouhal numbers obtained on models applicable to determination of the vortex shedding from different real life objects overflowed by wind (including bridge structures) is noted in work of Isaev et al. (2015) [15, 33].

The most precise and graphic experimental method of determining the Strouhal number is the method involving the analysis of periodic vortexes of the Karman vortex street in the wake of the overflowed body. A distinct picture of the development of the Karman vortexes is observed in the range of $100 \leq R e \leq 300$, which is explained by the absence of small casual turbulent pulsations in the area of flow lines near the Karman vortexes. At the Krylovsky State Scientific Research Centre a special hydrodynamic tunnel was manufactured on the model of the well-known Werle (1974) installation for visualization of the vortex flows at low Reinhold numbers. The formation of the Karman vortex street behind the overflowed body causes, under certain circumstances, intense self-excited oscillations of this body. Visualization of the vortex wake in the bridge span simulator is presented in Fig. 5 (a, b). 


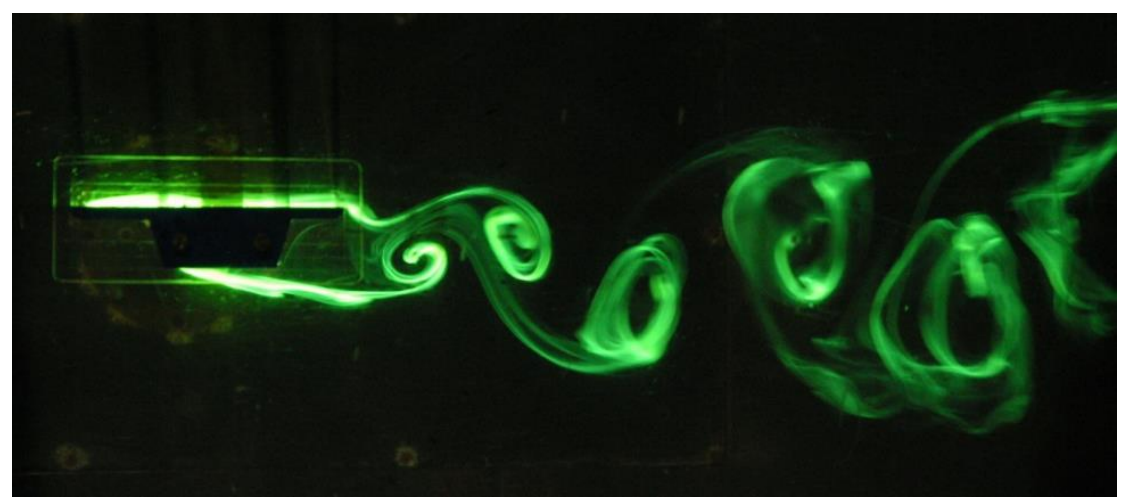

a)

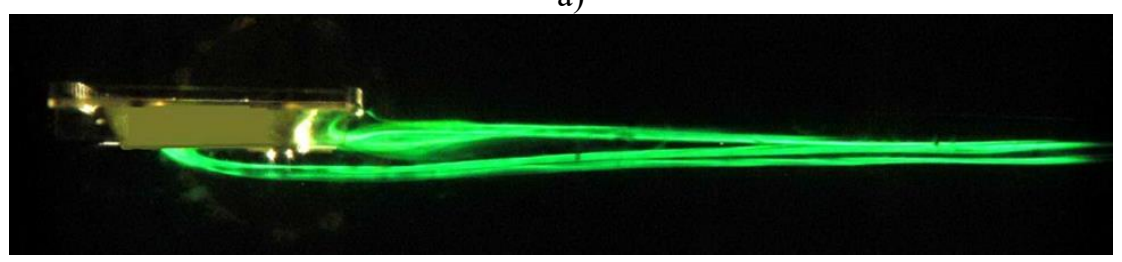

b)

Fig. 5. Vertical wake of the bridge: a) without using vortex destroyer; b) with using vortex destroyer.

The Strouhal number in the simulator experiment was found from the ratio (1) $S h=\frac{n \cdot h}{V}$, where $n$ is the vortex convergence frequency, $h$ is the transversal simulator size; $n$ determined by the formula:

$$
n=\frac{1}{\Delta t},
$$

where $\Delta t$ is the time period between two consecutive vortexes shedding from the simulator. The temporal gap between the simulator lift-off of two successive vortexes was computed by dividing the $L$ distance between two vortexes in the Karman street by the $V_{1}$ velocity of the vortex street relocation:

$$
\Delta t=\frac{L}{V_{1}}
$$

Taking the $V_{1}=0.8 V$ value corresponding to the outline overflowing with a fixed separation point, we get the ratio $S h=0.8 h / L$. Based on experimental data for the Volgogradsky Bridge span structure we find $S h=0.13$. For the span structures of different bridges the Strouhal number varies in the $0.11 \leq S h \leq 0.18$ range. The frequency of the induced aerodynamic force impacting the Volgogradsky Bridge span structure during its transversal overflowing by the air flow will depend on the wind velocity and will be determined by the ratio $n=0.13 \mathrm{~V} / \mathrm{h}$. The proper oscillation frequency of the Volgogradsky Bridge in the first oscillation form is $f=0.42 \mathrm{~Hz}$ [15]. When the vortex shedding frequency coincides with the proper oscillation frequency of the bridge, conditions emerge for the wind resonance to occur. These conditions will exist at wind velocity of $V=15 \mathrm{~m} / \mathrm{s}$. The bridge span length is $l=168 \mathrm{~m}$, sheet thickness $s=12 \mathrm{~mm}$, and span height $H=4.2 \mathrm{~m}$. Fig. 6 and Tabl. 1 show the bridge size and the rest of the basic data. 

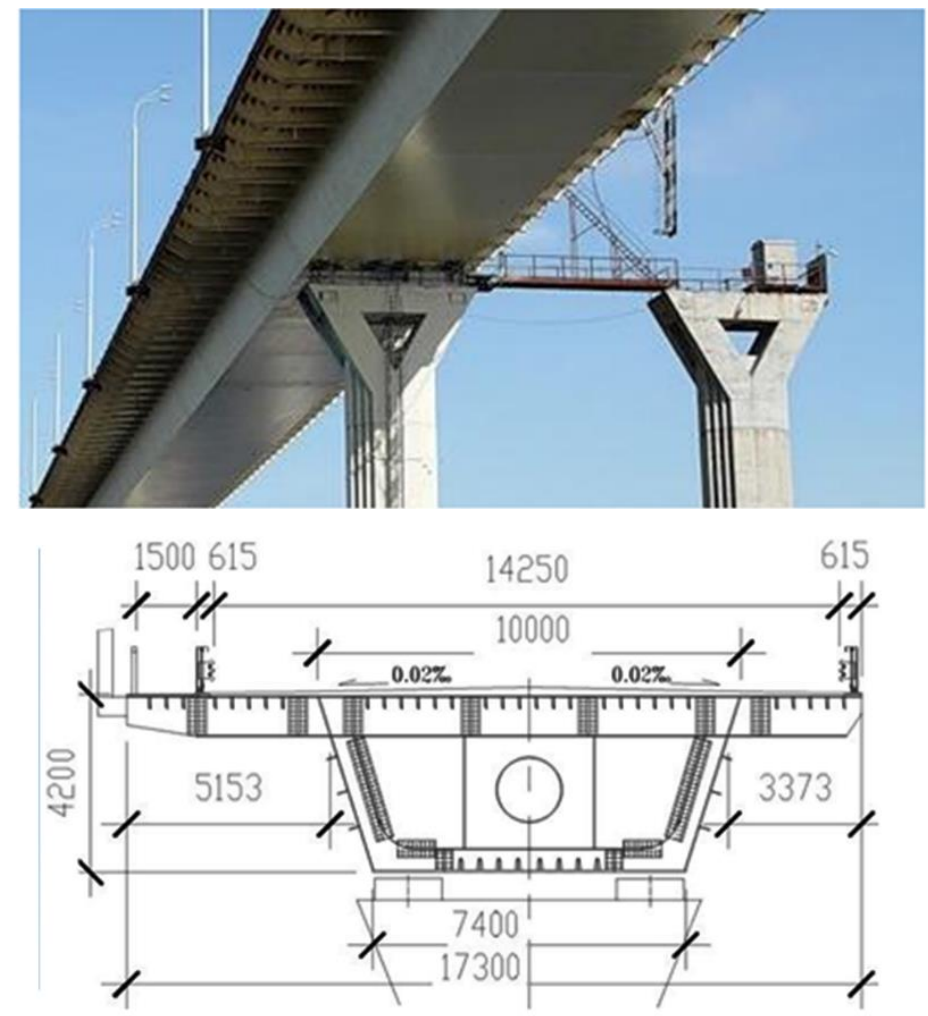

Fig. 6. Bridge size.

Table 1. Volgogradsky Bridge basic data.

\begin{tabular}{|l|c|}
\hline Girder cross-section area & $S=0,31 \mathrm{~m}^{2}$ \\
\hline \multirow{2}{*}{$\begin{array}{l}\text { Inertia moments relative to coordinate } \\
\text { axes }\end{array}$} & $J x=1.05 \mathrm{~m}^{4}$ \\
\cline { 2 - 2 } Section centre coordinates & $J y=3.40 \mathrm{~m}^{4}$ \\
\cline { 2 - 2 } & $y=2,31 \mathrm{~m}$ \\
\hline Span mass $168 \mathrm{~m}$ & $x=0 \mathrm{~m}$ \\
\hline Elasticity modulus & $850 \mathrm{t}$ \\
\hline
\end{tabular}

The vortex flutter computing method included the following stages: 1) determination of proper frequencies and oscillation forms of the structure under study; 2) determination of the wind flow vortex shedding frequencies for different velocities and the flow angles of incidence; 3) determination of possible resonance modes; 4) solution of the problem of interaction between the structure and the wind flow in choosing the oscillation form whose frequency is closest to that of vortex shedding.

The proper frequencies and bridge oscillation forms were determined using the ANSYS based on the assumption that the bridge is a multiple support girder. The first frequency proved to be $0.38 \mathrm{~Hz}$. The experimental frequency $f_{\text {exp }}=0.42 \mathrm{~Hz}$ was determined using information of prof. Salenko about the bridge oscillations [15]. The difference between the computation and experiment was $10 \%$. Subsequently, an experimental frequency was introduced into computations. 
At the next stage of investigation, the CFX software was used to determine the aerodynamic lifting force for angles of incidence [alfa] in the range from $0^{\circ}$ to $4^{\circ}$. In this calculation the bridge was treated as a solid body. The simulator took into account the enclosing guards along the roadway $(0.8 \mathrm{~m})$ since they influence the vortex shedding frequency. The computation employed the Menter SST turbulence simulator [34]. Based on these results, the lifting force oscillation periods and frequencies were determined. These oscillations result from an unstable flow in the wake of the overflowed bridge and emergence of the Karman vortex street (Fig. 7).

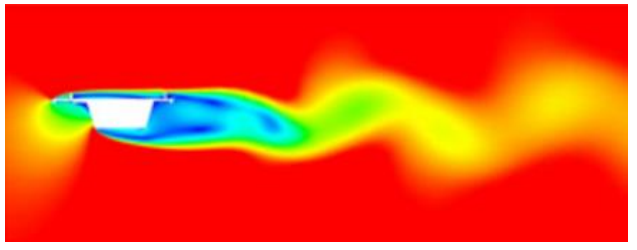

$[$ alfa $]=0^{\circ}, V=16 \mathrm{~m} / \mathrm{s}$

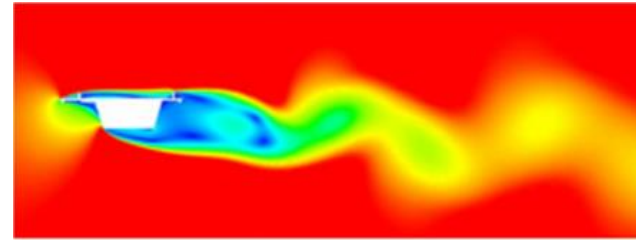

$[a l f a]=4^{\circ}, V=16 \mathrm{~m} / \mathrm{s}$

Fig. 7. Visualization of Volgogradsky Bridge wake.

The performed computations enabled determination of the Strouhal number and the velocity at which the vortex shedding frequency will coincide with that of the bridge proper oscillations. Tabl. 2 summarizes the results of computing the Strouhal number and the critical velocity that corresponds to the experimental frequency.

Table 2. Strouhal number computing.

\begin{tabular}{|l|c|c|}
\hline [alfa] & $0^{\circ}$ & $4^{\circ}$ \\
\hline$S h$ & 0.150 & 0.138 \\
\hline$V, \mathrm{~m} / \mathrm{s}$ & 14 & 15.3 \\
\hline
\end{tabular}

As a result, the final velocities at which the aeroelastic oscillations can occur were accepted as 13 and $14.6 \mathrm{~m} / \mathrm{s}$ for angles of incidence, respectively, $0^{\circ}$ and $4^{\circ}$. The supplied calculation results tally very well with the physical experiment data described above.

\section{Discussion}

The last stage of the investigation is the bridge structural calculation for aeroelastic oscillations. This results in the solution of the differential equation of the bridge oscillations in its first proper form under the influence of aerodynamic lifting force variable over time and dependent on those elastic oscillations:

$$
m y^{\prime \prime}+c y^{\prime}+k y=F\left(y, y^{\prime}, y^{\prime \prime}, t\right)
$$

In (5) $F\left(y, y^{\prime}, y^{\prime \prime}, t\right)$ is the aerodynamic lifting force, converted to the 1 st proper form, which is calculated using the FSI technology built in the CFX software. The $m, c, k$ parameters are the summarized mass, viscosity and rigidity corresponding to the 1 st form. Fig. 8 shows the results of calculating the bridge for aeroelastic oscillations at two angles of incidence. 


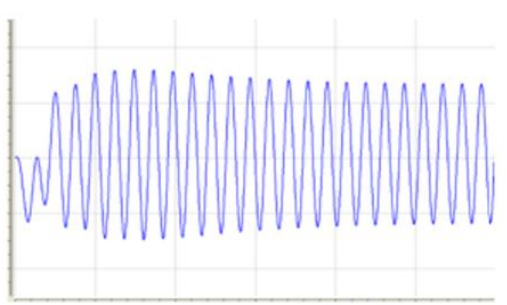

[alfa] $=0^{\circ} . V=13 \mathrm{~m} / \mathrm{s}, f=0.39 \mathrm{~Hz}$

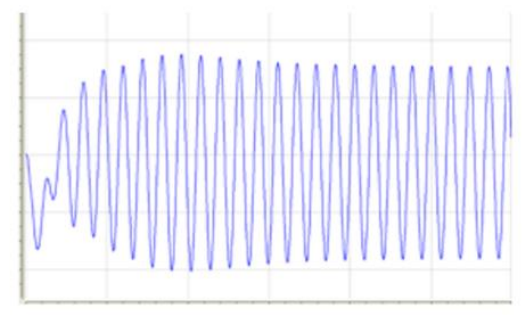

$\left[\right.$ alfa] $=4^{\circ} . V=14.6 \mathrm{~m} / \mathrm{s}, f=0.40 \mathrm{~Hz}$

Fig. 8. Volgogradsky Bridge oscillation process.

The charts show the established oscillations corresponding to the coverage of the frequency of vortex shedding of proper bridge oscillation frequency. It means that frequencies become equal. The oscillation amplitudes amounted to $280 \mathrm{~mm}$ and $380 \mathrm{~mm}$ for angles of incidences from, respectively, $0^{\circ}$ to $4^{\circ}$. In actual fact, they were roughly equal to $400 \mathrm{~mm}$. Despite the oscillations with such a large amplitude, the bridge did not collapse and remained strong. Special checks showed that it is fit for further use. However, the significant exceeding of design stresses caused by oscillations could reduce the strength resource of the bridge.

\section{Conclusions}

The results of investigations carried out on the Volgogradsky Bridge are methodologically applicable to different girder bridges with a low flexural rigidity. Such technologies are widely used in bridge construction. Among such bridges are, for instance, Coronado Bridge (USA), Øresund Bridge between Denmark and Sweden, Great Belt Bridge and East Bridge (between Fyn and Sjælland, Denmark), Confederation Bridge across Northumberland Strait (Canada), Ponte Rio-Niterói across Baía da Guanabara (Brazil), Trans Tokyo Bay Motorway (Japan) and others. The experiments and calculations showed that the cause of such a significant sway of the Volgogradsky Bridge was the vortex flutter. In this case an objectionable and rare combination occurred that included the bridge section size, Strouhal number, and wind direction and velocity, which led to the coincidence of vortex shedding frequency with that of structure. This resulted in the self-excided oscillations (flutter) of the bridge. The proposed methods can minimize risks for the construction of long-span girder bridges, ensuring the precise estimation of their subsequent safe operation.

\section{References}

1. I. Kavrakov \& G. Morgenthal, J. of Fluids and Struct. 82, 59-85 (2018). https://doi.org/10.1016/j.jfluidstructs.2018.06.013

2. G. Prasad, INCAS Bullet. 11(4), 133-138 (2019). https://doi.org/10.13111/20668201.2019.11.4.12

3. Y. C. Fung, An Introduction to the Theory of Aeroelasticity (Dover Publications, Mineóla, ]New York, 2008).

4. E. H. Dowell, A Modern Course in Aeroelasticity (Springer, Cham, 2015). https://doi.org/10.1007/978-3-319-09453-3

5. L. Sanpaolesi, P. Croce (Ed.), Handbook 4: Design of Bridges: Guide to the Basis of Bridge Design Related to Eurocodes Supplemented by Practical Examples ([S.n.], Pisa, 2005).

6. B. Alesson, Understanding Bridge Collapse (CRC Press, Boca Raton, FL, 2014). 
7. N. B. Bethea, The Science of a Bridge Collapse (Cherry Lake Publ., Ann Arbor, Michigan, 2015).

8. G. F. Myers, A. M. Ghalib, Atkins Techn. J. 7, 83-92 (2012).

9. S. Kaneko, T. Nakamura, F. Inada, M. Kato, K. Ishihara, T. Nishihara, ... M. A. Lanthjem, Flow-induced Vibrations. Classifications and Lessons from Practical Experiences (2nd ed.) (Academic Press, London, Waltham, Mass., 2014).

10. Y. Ge, H. Tanaka, Long-span bridge aerodynamics. In Y. Tamura, A. Kareem (Eds.), Advanced Structural Wind Engineering (pp 85-120) (Springer, Tokyo, 2013). https://doi.org/10.1007/978-4-431-54337-4_4

11. G. Diana, D. Rocchi, T. Argentini, S. Muggiasca, J. Wind Eng. Ind. Aerodyn. 98, 363374 (2010). doi:10.1016/j.jweia.2010.01.003

12. M. S. Mohammadi \& R. Mukherjee, Wind Loads on Bridges. Analysis of a Three Span Bridge Based on Theoretical Methods and Eurocode 1 (Royal Institute of Technology, Stockholm, 2013)

13. O. Poddaeva, A. Fedosova and J. Gribach, E3S Web of Conf. 97, Article 03030 (2019). https://doi.org/10.1051/e3sconf/20199703030

14. P. Churin \& A. Fedosova, IOP Conf. Ser.: Mater. Sci. Eng. 365, Article 052009 (2018).

15. Yu. A. Gosteev, A. D. Obukhovskiy, S. D. Salenko. Magaz. of Civ. Eng. 49(5), 63-72 (2014). https://doi.org/10.5862/MCE.49.7

16. S. V. Petinov, In-Service Fatigue Reliability of Structures (Springer, Cham, 2018). https://doi.org/10.1007/978-3-319-89318-1

17. T. Stathopoulos, C. Baniotopoulos, R. Scanlan, Wind Effects on Buildings and Design of Wind-Sensitive Structures (Springer, Wien; New York, 2007). https://doi.org/10.1007/978-3-211-73076-8

18. M. van Dyke, An Album of Fluid Motion (Parabolic Press, Stanford, CA, 2012).

19. Y. S. Matter; T. T. Darabseh; A.-H. I. Mourad, Meccanica: An Intern. J. of Theor. and Appl. Mech. AIMETA, 53(15), 3673-3691 (2018). https://doi.org/10.1007/s11012-0180915-2

20. D. Proske, Bridge Collapse Frequencies versus Failure Probabilities. Risk Engineering (Springer, Cham, 2018). https://doi.org/10.1007/978-3-319-73833-8_6

21. A. Hodgkinson, P. Cooper, Bridge dynamics. In G. Parke, N. Hewson (Eds.), ICE Manual of Bridge Engineering (pp. 113-144) (Thomas Telford, London, UK, 2008). https://doi.org/10.1680/mobe.34525.0113

22. G. T. Michaltsos, I. G. Raftoyiannis, Bridges' Dynamics (Bentham Science Publishers, Sharjah, U.A.E.; Oak Park, IL, 2012).

23. B. L. Kutter \& D. L. Wilson, Intern. J. of Phys. Model. in Geotech. 6(1), 1-12 (2006). https://doi.org/10.1680/ijpmg.2006.060101

24. P. A. Sanders, D. K. MacKenzie, C. J. Walker, Proceed. of the ICE - Bridge Eng. 163(2), 49-58 (2010). https://doi.org/ 10.1680/bren.2010.163.2.49

25. Jones V, Howells J (2008) Suspension bridges. In G. Parke, N. Hewson (Eds.), ICE Manual of Bridge Engineering (pp. 383-419) (Thomas Telford, London, UK, 2008). https://doi.org/10.1680/mobe.34525.0383

26. W. Shyy, Y. Lian, J. Tang, Aerodynamics of Low Reynolds Number Flyers (Cambridge University Press, Cambridge, 2006).

27. F. Auteri, A Quasi-optimal spectral method for turbulent flows in non-periodic geometries. In A. Talamelli, M. Oberlack, J. Peinke (Eds.), Progress in Turbulence V: Proceedings of the iTi Conference in Turbulence 2012 (pp. 227-231) (Springer, Cham, 2014). https://doi.org/10.1007/978-3-319-01860-7_37

28. E. Smirnova \& S. Savin, IOP Conf. Ser.: Mat. Sci. and Eng. 652(1), Article 12010 (2019). https://doi.org/10.1088/1757-899X/652/1/012010 
29. E. Smirnova, S. Savin \& D. Larin, MATEC Web Conf. 285, Article 00017 (2019). https://doi.org/10.1051/matecconf/201928500017

30. S. Savin \& E. Smirnova, World Appl. Sci. J. 23(11), 1448-1454 (2013). https://doi.org/10.5829/idosi.wasj.2013.23.11.13161

31. R. S. Hobbs, Catastrophe to Triumph: Bridges of the Tacoma Narrows (Washington State University Press, Pullman, US, 2006).

32. G. Arioli \& F. Gazzola, Communic. in Nonlin. Sci. and Numer. Simul. 42, 342-357 (2017). https://doi.org/10.1016/j.cnsns.2016.05.028

33. S. A. Isaev, A.S. Guzeev, S. Z. Sapozhnikov, V. Y. Mityakov, A. V. Mityakov, Magaz. of Civ. Eng. 88(2), 438-454 (2015). https://doi.org/10.1007/s10891-015-1210-x

34. R. Schiestel, Modeling and Simulation of Turbulent Flows (Wiley-ISTE, Hoboken, NJ, US, 2008). 